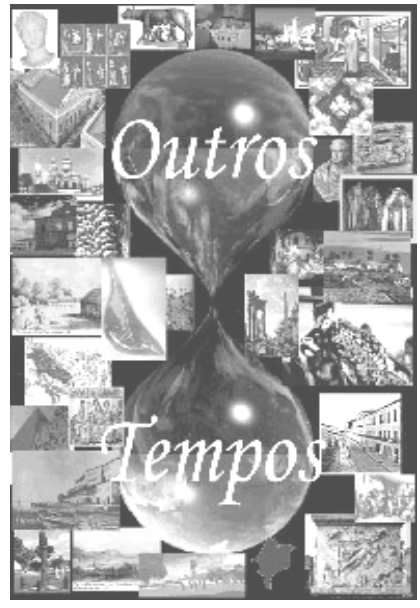

\title{
O NACIONALISMO NA EXPERIÊNCIA DEMOCRÁTICA BRASILEIRA
}

\author{
Charles Sidarta Machado Domingos \\ Mestrando em História pela Universidade Federal do Rio Grande \\ do Sul (UFRGS) \\ Bolsista CAPES sob a orientação da Prof. Dra. Carla Brandalise.
}

Resumo: Este artigo aborda o conceito de nacionalismo como categoria de análise para o período de 1945-1964 no Brasil. Ao estudar esse longo período, optamos por dar ênfase às mudanças pelas quais o conceito passou, principalmente, ao longo dos anos de 1951 a 1964. Ao utilizarmos as concepções de Eric Hobsbawm sobre o caráter histórico do nacionalismo, pretendemos demonstrar de que forma se realizaram as mudanças nos usos e percepções a respeito do fenômeno, sem perdermos de vista sua importância nos embates políticos pela disputa do poder no Brasil.

Palavras-chave: Nacionalismo; ISEB; História do Brasil; História Política.

Abstract: This article is about the nationalism concept as analysis category for the period of 1945-1964 in Brazil. During this period we chose to emphasize the changes wich the concept has been through, specially, through the years from 1951 to 1964. By utilizing Eric Hobsbawm's conceptions about nationalism historical character, with the intent of showing how the changes happened in the uses and perceptions of the phenomena, without forgetting it's importance in the political battles in the dispute for power in Brazil.

Keywords: Nationalism; ISEB; History of Brazil; History Politics.

\section{INTRODUÇÃO}

Neste trabalho, pretendemos esboçar uma divisão temporal em três partes para o nacionalismo brasileiro do período 1945-1964. Embora existam elementos capazes de serem definidos como "nacionalismo", no transcorrer do Governo Eurico Gaspar Dutra (1946-1950), ${ }^{1}$ optamos por não, enfatizar este período em nossa análise. Esta decisão se deve, principalmente, ao fato de as bases de apoio aos Estados Unidos da América (EUA)

\footnotetext{
${ }^{1}$ Vânia Maria Losada Moreira nos alerta que o nacionalismo, enquanto movimento social e político, começa a ganhar força já em 1943 (ainda na ditadura do Estado Novo) com a campanha "O petróleo é nosso". Seu êxito se completa em 1953, com a criação da Petrobrás. (MOREIRA, 2003, p. 169-170).
} 
- ainda percebidas como heróis antifascistas - deterem grande hegemonia no conjunto da sociedade.

Antes de começarmos a discussão sobre as especificidades de cada um dos três períodos do nacionalismo brasileiro de 1945 a 1964 - temos consciência da arbitrariedade dos marcos temporais e conjunturais por nós propostos e de um certo artificialismo que essa escolha engendra - optamos por fazer uma breve discussão sobre o fenômeno nacionalismo em seu sentido histórico mais amplo, por entendermos ser um dos conceitos mais importantes da História Política. Após essa breve incursão por alguns clássicos da historiografia sobre o tema, traremos a discussão novamente para o cenário brasileiro.

\section{A ABORdagem CLÁSSICA DO NACIONALISMO.}

Um dos conceitos mais instigantes da História Política é o de nacionalismo. Raras são as ocasiões nas quais ele é utilizado de forma exclusiva: via de regra, está sempre acompanhado de conceitos ou expressões correlatas, tais como nação, Estado-nação, identidade nacional e sentimento nacional.

O debate teórico sobre o nacionalismo aparece, pelo menos, desde os fins do século XIX e primeiro quartel do século $X X{ }^{2}$ Sua atualidade é sempre presente. ${ }^{3}$ No entanto, um marco no debate historiográfico pode ser encontrado, sobretudo, a partir dos anos 1980.

É de 1983 a obra "Nações e nacionalismo: trajectos", de Ernest Gellner. Nesse trabalho, o autor aprofunda e atualiza algumas questões que já levantava, desde a década de 1960. Obra de iminente caráter sociológico - em boa medida tributário dos ensinamentos de Max Weber ${ }^{4}$ - e de forte vinculação com a teoria da modernização ${ }^{5}$, Gellner procura explicar o fenômeno nacionalismo dentro de parâmetros objetivos, com elementos concretos; no caso, a sociedade industrial, pois é nela que "o nacionalismo está enraizado num determinado tipo de divisão do trabalho, complexo, persistente e cumulativamente em mudança" (GELLNER, 1983, p.44) ${ }^{6}$ capaz de moldar, com

\footnotetext{
${ }^{2}$ Ver os textos de Lord Acton e Otto Bauer, na coletânea organizada por BALAKRISHNAN, Gopal. Um mapa da Questão Nacional. Rio de Janeiro: Contraponto, 2000, p. 23-43; 45-83.

${ }^{3}$ No momento em que escrevo este artigo, a ONU realiza uma sessão extraordinária para avaliar a declaração de independência de Kosovo.

${ }^{4}$ É o caso, fundamentalmente, da noção de racionalidade (GELLNER, 1983, p. 38-40).

${ }^{5}$ Em linhas gerais, a teoria da modernização preconiza a passagem da sociedade agrária para a sociedade industrial, com o aparecimento das migrações e da sociedade de massas.

${ }^{6}$ Os grifos são nossos, para demonstrar como, mesmo em uma análise mais sociológica, a perspectiva dinâmica do conceito nacionalismo já se encontrava presente.
} 
homogeneidade, a sociedade a partir de um sistema educacional direcionado para esse fim, “transformando todos em 'letrados', fazendo desta classe potencialmente universal uma classe realmente universal, e assegurando que todos, sem excepção, sejam ensinados por ela" (GELLNER, 1983, p. 55).

O autor afirma que "o monopólio da educação legítima é agora mais importante e mais central do que o monopólio da violência legítima" (GELLNER, 1983, p. 59), deslocando aquele que era um dos elementos fundamentais do Estado Absolutista europeu, em razão do nacionalismo. ${ }^{7}$ Não concordamos com a dimensão dessa afirmação, pois, mesmo com a importância inconteste da educação para os propósitos nacionalistas, é necessário lembrar que, tanto na Europa dos séculos XVIII e XIX (e até mesmo XX, na Rússia até a década de 1930) quanto no Brasil do século XX, a alfabetização em massa percorreu um caminho repleto de obstáculos. A nosso ver, a afirmação está muito mais relacionada com uma perspectiva teórica do que empírica da realidade.

Em trabalho mais recente, ao se referir à sociedade industrial avançada, Gellner afirma que "o crescimento econômico é o primeiro princípio de legitimação desse tipo de sociedade" (GELLNER, 2000, p. 114-115). É a partir do desenvolvimento da economia, portanto, que o conceito político de nacionalismo se organiza, tendo como "segundo princípio de legitimidade a nacionalidade" (GELLNER, 2000, p. 115), caso bastante semelhante ao que ocorre no Brasil, durante o período que investigamos.

A perspectiva de Gellner é estimulante, para o estudo do nacionalismo, por deter-se em elementos socialmente construídos, como a industrialização e a escola. A partir dessas constatações, o autor descortina como alguns critérios utilizados para caracterizar o nacionalismo - como a linguagem em sentido estritamente antropológico - são problemáticos para formar a definição do conceito (GELLNER, 1983, p. 72). Para Gellner, os vínculos mais fortes em torno do nacionalismo são os políticos. Através deles que a sociedade industrial (ele quase não utiliza a nomenclatura capitalismo) define sua soberania. No entanto, algumas importantes questões ficaram de fora de sua análise, como o sentimento de nacionalidade.

Coincidentemente, no mesmo ano de 1983, é publicada a primeira edição de outro clássico do estudo do nacionalismo: o livro de Benedict Anderson. Seu título,

\footnotetext{
${ }^{7}$ Os outros elementos fundamentais do Absolutismo europeu eram o monopólio da cobrança de impostos e o monopólio da cunhagem de moedas.
} 
"Comunidades Imaginadas", dá uma boa dimensão da abordagem realizada pelo autor. ${ }^{8}$ Para Anderson, tanto "a nacionalidade, ou, como se prefira dizer, devido às múltiplas significações dessa palavra, nation-ness, bem como o nacionalismo, são artefatos culturais de um tipo peculiar" (ANDERSON, 1989, p. 12). Essa peculiaridade a que Benedict Anderson se refere está calcada no contexto do capitalismo. E possivelmente seja esta a grande inovação de seu trabalho: analisar, de forma articulada, a cultura enquanto elemento antropológico com a emergência e desenvolvimento do capitalismo, abrindo espaços para elementos subjetivos, que estavam ausentes da até então perspectiva hegemônica, protagonizada por Ernest Gellner.

Para Anderson, a nação é "uma comunidade política imaginada - e imaginada como implicitamente limitada e soberana" (ANDERSON, 1989, p. 14). Dialoga diretamente com Gellner, ao criticá-lo por associar a invenção das nações a "contrafação" e "falsidade", quando deveria interpretar essa invenção como "imaginação" e "criação". E explica a nação como "imaginada, porque nem mesmo os membros das menores nações jamais conhecerão a maioria de seus compatriotas, nem os encontrarão, nem sequer ouvirão falar deles, embora na mente de cada um esteja viva a imagem de sua comunhão" (ANDERSON, 1989, p. 15). Com elegância e clareza, Anderson elabora, como acabamos de perceber, a explicação daquilo que, daqui por diante, nos referiremos como sentimento de nacionalidade, ou sentimento nacional. Além disso, a nação é imaginada como soberana pelo momento na qual ela nasceu, época do Iluminismo e da Revolução Francesa, pautada pela participação e cidadania. E, por fim, é imaginada como comunidade, por ser capaz de produzir um sentimento de pertencimento, com um companheirismo profundo e horizontal, fraterno como um dos componentes da tríade discursiva revolucionária.

O autor inova também ao afirmar que "o que proponho é que o nacionalismo deve ser compreendido, pondo-o, lado a lado, não com ideologias políticas abraçadas conscientemente, mas com sistemas culturais amplos que o precederam, a partir dos quais - bem como contra os quais - passaram a existir" (ANDERSON, 1989, p. 20). Esses sistemas culturais são a comunidade religiosa e o reino dinástico, além de concepções sobre o tempo produzidas pela análise de uma das fontes privilegiadas da História da Cultura, que são produzidas pela literatura de ficção. No entanto, mesmo fazendo as necessárias relações com o desenvolvimento do capitalismo, em especial o capitalismo

\footnotetext{
${ }^{8}$ Infelizmente, o livro com o qual trabalhamos não foi traduzido dessa maneira. Mas a fama que esse trabalho conquistou imortalizou o título original em praticamente todas as discussões sobre a temática.
} 
editorial, o autor fica por demais apegado ao papel da vulgarização da língua como elemento de unidade do nacionalismo, mesmo que em alguns momentos, se aproxime do que Gellner percebeu com relação à alfabetização (ANDERSON, 1989, p. 91).

Sem dúvida, um dos mais brilhantes historiadores de todos os tempos, Eric Hobsbawm, fecha a tríade dos clássicos do nacionalismo a partir de suas reflexões de 1990. Embora suas análises tenham muitas semelhanças com as de Ernest Gellner, notadamente a busca por elementos objetivos e a recusa ao entender o nacionalismo por um viés estritamente ligado a língua, Hobsbawm avança no estudo do nacionalismo ao abordá-lo enquanto fenômeno histórico, possuindo, desta maneira, uma gênese, um desenvolvimento, e tendo, um dia, um final.

Assim como Ernest Gellner e Benedict Anderson, Hobsbawm vê o início do nacionalismo no século XVIII como fenômeno do capitalismo. Enquanto Gellner afirma que "a sociedade inteira deve ser perpassada por uma só cultura superior padronizada, caso pretenda funcionar" (GELLNER, 2000, p. 117), Hobsbawm avança ao entender que, mesmo que as línguas só possam ser padronizadas através da imprensa (como diz Anderson) ou pela escolaridade (o cerne de Gellner), para o historiador, não se pode perder de vista que as nações são construídas pelo alto (como afirma Gellner), porém, não podem ser compreendidas sem serem analisadas de baixo, em razão das esperanças, necessidades, aspirações e interesses das pessoas comuns. No início do nacionalismo, próximo à Revolução Francesa, a nação não tinha a ver "com etnicidade, língua comum, religião, território e lembranças históricas comuns" (HOBSBAWM, 2002, p. 33). Para aqueles homens e mulheres, o que compunha a essência de uma nação era o exercício da cidadania, o sentido de pertencimento, como bem descreveu Benedict Anderson.

Para Hobsbawm, o apogeu do nacionalismo se dá na Europa Ocidental no período do pós Primeira Guerra Mundial, até 1950. A partir da formação da Liga das Nações, como resposta, ao colapso dos impérios multinacionais da Europa Central e Oriental e da Revolução Russa, o princípio de nacionalidade do presidente estadunidense Wilson fez com que as fronteiras dos Estados coincidissem com as fronteiras das nacionalidades e das línguas. Ao longo do tempo, essa divisão artificial traria novas transformações ao nacionalismo, em especial ao dos Estados mais recentes, como Alemanha e Itália, pois “o nacionalismo sofreu uma mutação: de um conceito associado ao liberalismo e à esquerda, para um movimento da direita chauvinista, imperialista e xenófoba, ou mais precisamente, da direita radical” (HOBSBAWM, 2002, p. 144). Processo de transformação semelhante 
poderia ser descrito como o acontecido no Brasil: na passagem do nacionalismo do período democrático para o nacionalismo ufanista, dos ditadores militares, que assumiram o Estado com o golpe civil-militar de 01 de abril de 1964. Hobsbawm, ao analisar o período entreguerras na Europa, aponta que "o nacionalismo adquiriu uma forte associação com as esquerdas durante o período antifascista, associação essa que foi reforçada subsequentemente pela experiência da luta anti-imperialista nos países coloniais" (HOBSBAWM, 2002, p. 176), o que nos permite relacionar o nacionalismo e as esquerdas no Brasil, em razão, principalmente, de um discurso comum anti-imperialista, ao longo do período 1945-1964.

Para o autor, os nacionalismos de fins do século XX passaram a ser "essencialmente negativos, ou melhor, separatistas. Daí, a insistência colocada nas diferenças étnicas e lingüísticas, que aparecem, às vezes, de forma individual ou combinada com a religião" (HOBSBAWM, 2002, p. 196). No entanto, reafirma o caráter histórico do nacionalismo mais recentemente, ao nos advertir que, embora "nada de bom advirá disso", também "não vai durar para sempre" (HOBSBAWM, 2000, p.282). Embora o nacionalismo brasileiro não tenha se desenvolvido de forma separatista como o europeu, sofreu significativas mudanças ao longo de sua existência por ser um fenômeno histórico. É a partir dessa contribuição de Eric Hobsbawm como instrumento de análise que nos valeremos no desenvolvimento deste artigo, de forma consciente, sem nos preocuparmos em seguir o mesmo padrão evolutivo do nacionalismo europeu, pois há muito já sabemos que as realidades históricas seguem seus próprios rumos.

\section{O NACIONALISMO NO INÍCIO DA DÉCADA DE 1950.}

Segundo Simon Schwartzman, foi a partir de agosto de 1952 que um grupo de intelectuais começou a se reunir para discutir os grandes problemas da sua época, em especial os relativos às formas de o país superar o subdesenvolvimento. Como o local de encontro desse grupo era o Parque Nacional de Itatiaia - entre o Rio de Janeiro e São Paulo - ele ficou conhecido como Grupo de Itatiaia. E, já, a partir de 1953, esse grupo articulouse para criar o Instituto Brasileiro de Economia, Sociologia e Política (IBESP) e editar os Cadernos de Nosso tempo. Ainda segundo Simon Schwartzman “A importância do IBESP e dos Cadernos é que eles contêm, no nascedouro, toda a ideologia do nacionalismo, que ganharia força cada vez maior no país nos anos subseqüentes, e serviriam de ponto de 
partida para a constituição do Instituto Superior de Estudos Brasileiros (ISEB)" (SCHWARTZMAN, 1979, p. 3).

Para Simon Schwartzman - e aqui o seu trabalho se mostra extremamente pertinente para nossos objetivos principais - os intelectuais do IBESP tinham em seu horizonte de análises

a grande preocupação do IBESP com temas relativos à política internacional (...) parece responder ao clima particularmente agudo da Guerra Fria no início da década de 50, não permanecendo no tempo a não ser no esforço de aproximação com os novos países africanos, e uma idéia de uma política externa independente que não deixaria de produzir seus frutos (SCHWARTZMAN, 1979, p. 4). ${ }^{9}$

No estudo de Caio Navarro de Toledo, tornado clássico sobre o ISEB, suas preocupações são de caráter ideológico e filosófico, como ele mesmo faz questão de esclarecer no prefácio da obra. Com refinada análise, utilizando-se de um aparato conceitual baseado em ideologia e alienação, conceitos marxistas muito bem trabalhados, sua obra privilegia aquilo que consideraremos o segundo momento do nacionalismo, quer seja, o nacional-desenvolvimentismo. O próprio autor nos adverte quanto a isso:

Detivemo-nos particularmente no exame dos trabalhos isebianos publicados durante o período chamado de desenvolvimentismo (governo Juscelino Kubitschek - 1956-1960), embora sejam assinaladas algumas referências que apontam para (e interpretam) outros momentos da vida da instituição (TOLEDO, 1997, p. 26).

Para Toledo, "a idéia-matriz que permitiu a criação do ISEB estava sendo gestada desde os primeiros anos do último governo Vargas. Pode-se mesmo afirmar que o ISEB sucedeu o Instituto Brasileiro de Economia, Sociologia e Política (IBESP)" (TOLEDO, 1997, p. 203). Toledo se refere ao Decreto $\mathrm{n}^{\circ}$ 57.608, datado de 14 de julho de 1955, assinado pelo presidente João Café Filho, como sendo o momento de fundação do ISEB. E acrescenta outros nomes componentes do IBESP que não constavam na lista de Schwartzman, como Álvaro Vieira Pinto, Nelson Werneck Sodré e Roland Corbisier, os quais, somados aos nomes de Alberto Guerreiro Ramos, Candido Mendes de Almeida e Hélio Jaguaribe, formariam o núcleo dos intelectuais de "primeira hora" do ISEB.

Caio Navarro de Toledo separa o ISEB em três fases: 1) da criação até a "encampação" juscelinista (um curto período, de aproximadamente 6 meses); 2) o qüinquiênio juscelinista (no qual aprofunda seu trabalho); 3) o período que acompanha as

\footnotetext{
${ }^{9}$ Quando o autor se refere a "não permanecendo no tempo..." está se referindo, provavelmente, ao fato de essa preocupação não estar entre as preocupações centrais dos intelectuais do ISEB no período de 1956-1960.
} 
Reformas de Base (nesse período, a análise é extremamente superficial; seria algo correspondente aos Governos Jânio Quadros e João Goulart) (TOLEDO, 1997, p. 205209). ${ }^{10}$ Toledo faz a seguinte afirmação, a respeito da fase "C": “A perspectiva nacionalista - decisiva no momento anterior - aqui se encontra, se não negada, pelo menos sensivelmente atenuada" (TOLEDO, 1997, p. 209). Não estamos de acordo com essa afirmação, por entendermos que nessa fase o nacionalismo se radicaliza, à esquerda do espectro político"11.

Outros elementos que favoreceram o desenvolvimento do nacionalismo nesse início dos anos 1950 podem ser encontrados a partir da Campanha do Petróleo, como apontado por Octávio Ianni (IANNI, 1971, p. 66). Além disso, o nacionalismo ganha ainda mais força a partir do suicídio do presidente Getúlio Vargas, em 1954, e da divulgação da sua carta-testamento, fator de mobilização popular até então desconhecido na sociedade brasileira (PÉCAUT, 1990, p. 100). No plano das relações internacionais, já se fazia presente, no interregno Café Filho, a busca pelo "restabelecimento de relações comerciais com a China e os países do Leste Europeu" (ALMEIDA, 2006, p. 40), com base em princípios da soberania nacional, e que mais tarde seriam difundidos e implementados pela Política Externa Independente.

A soma desses diversos elementos fez com que, segundo Lucília de Almeida Neves, as décadas de 1940 e 1950 tenham sido cheias de otimismo, almejando-se “implementar um projeto de nação comprometido, principalmente, com o desenvolvimento social" (NEVES, 2001, p. 171). É essa perspectiva que abordaremos no segundo momento do nacionalismo brasileiro durante a experiência democrática.

\section{O NACIONAL-DESENVOLVIMENTISMO.}

Segundo Francisco Weffort, é a partir de 1956 que o nacionalismo se consubstancia, pois "o nacionalismo constitui-se, sem dúvida, a partir do governo Kubitschek, em centro de polarização ideológica" (WEFFORT, 2003, p. 24). Chegando o

\footnotetext{
${ }^{10} \mathrm{Em}$ trabalho realizado quando do cinqüentenário da fundação do ISEB, em 2005, aproximadamente 28 anos depois da publicação da $1^{a}$ edição de "Fábrica de Ideologias", Caio Navarro de Toledo aborda especificamente o Instituto durante o Governo Goulart. Veremos isso mais adiante.

${ }^{11}$ Essa afirmação de Toledo, estranhamente, destoa do que ele afirma ao longo dos capítulos 5 e 6 de sua obra; na sua análise, em especial nas páginas 157-166 e 184-188, o autor demonstra a própria crítica realizada por alguns isebianos, como Álvaro Vieira Pinto e Osny Pereira Duarte, que já fazem a denúncia sobre a subordinação do nacional ao desenvolvimento ao longo do qüinquiênio juscelinista, e o papel que os próprios intelectuais do ISEB tiveram nesse processo.
} 
mesmo autor a afirmar que "as posições políticas passaram a se definir em razão do nacionalismo" (WEFFORT, 2003, p. 24-25). O nacionalismo, dessa maneira, evidencia-se como o elemento definidor da vida política do Brasil, para o período. É a partir dele que, via de regra, tanto os partidos políticos quanto as demais formas de organização social vão definir-se no espectro político. O nacionalismo, é, pois, dentro de nosso marco temporal, o elemento constitutivo das disputas pelo poder, nos mais diversos níveis.

Caio Navarro de Toledo tem, em seu livro, mais esse mérito. Mesmo que ele saiba, que no fim da década de 1970, o nacional-desenvolvimentismo foi mais associado ao capital externo privado do que ao nacional, ele se preocupa em demonstrar, a partir da análise das obras dos intelectuais do ISEB, como estes "forjaram" o nacionaldesenvolvimentismo em bases ideológicas. Toledo sustenta, em última instância, que os membros do ISEB - imbuídos de um sentido de mudança para a sociedade brasileira, e entendendo como sendo papel dos intelectuais interferirem em prol dessa mudança pretendiam "urgentemente, agir; porém, procuram fazê-lo por meio do único instrumento que lhes está à disposição: a elaboração teórica, ou melhor, o pensamento ideológico" (TOLEDO, 1997, p. 123). A elaboração de uma ideologia genuinamente nacional, visando superar o subdesenvolvimento, era o que o ISEB, através de seus pensadores, pretendia realizar. Fabricar uma ideologia seria a sua função.

No entanto, Caio Navarro de Toledo, ao longo de seu trabalho, aponta as incongruências na fabricação dessa ideologia, a saber, o nacional-desenvolvimentismo. Contrariando as definições marxistas de ideologia, em especial as da vertente do próprio Marx de A Ideologia Alemã, os intelectuais do ISEB (com exceção de Nelson Werneck Sodré) pretendiam elaborar uma ideologia a priori; organizar um conjunto de idéias relativamente ordenadas que possibilitassem "desempenhar um papel ativo na transformação de toda a sociedade, unificando os interesses gerais da nação" (TOLEDO, 1997, p. 117). Excetuando-se Nelson Werneck Sodré, os demais isebianos não tinham no seu horizonte conceitual a ideologia como uma forma de dominação; para eles, a ideologia não passava de elucubração teórica capaz de mostrar os caminhos corretos a serem seguidos na direção de um fim nobre, qual seja: a "necessidade da implantação definitiva do capitalismo como superação do subdesenvolvimento" (TOLEDO, 1997, p. 156). Perspectiva que Nelson Werneck Sodré também tinha sobre o nacionalismo, de acordo com a visão do Partido Comunista Brasileiro, que buscava, nesse período, a revolução burguesa no Brasil. Para esse historiador (ao menos nesse período), o nacionalismo "não 
foi inventado, não surge da imaginação de uns poucos, nem vive da teoria, mas da prática" (TOLEDO, 1997, p. 73). Nunca é demais lembrar que, tanto os isebianos, quanto os membros do PCB, viam a implantação do capitalismo como a afirmação da industrialização; para esses dois grupos, nesse momento, o principal adversário do desenvolvimento brasileiro seria o latifúndio agrário-exportador. ${ }^{12}$

Para Caio Navarro de Toledo, o nacional-desenvolvimentismo tem início e fim com o Governo Juscelino Kubitschek, ${ }^{13}$ mesmo que elaborado por uma instituição relativamente autônoma do governo (Toledo enfatiza que a ideologia nacionaldesenvolvimentista é fruto do ISEB, e não do governo; mesmo que esse tivesse encampado suas formulações). O fim do Governo JK seria o fim das ilusões que o capitalismo pregou aos isebianos. O fim do nacional-desenvolvimentismo está relacionado com a percepção de que o desenvolvimento veio para poucos e não para toda a nação, como imaginavam os membros do ISEB. Ao sobressair o desenvolvimento, em relação ao nacional, percebeu-se que tudo não passara de ilusão. Essa crítica passou a ser realizada a partir do último ano do Governo JK, em especial, a partir da eleição de Jânio Quadros e da derrota de Henrique Teixeira Lott, em 1960, abrindo o período que Toledo considerou como pósdesenvolvimentista.

Escapa, todavia, da perspectiva de Caio Navarro de Toledo, que esse período, por ele denominado de pós-desenvolvimentista, mantém firmes contornos nacionalistas. Mesmo com a crítica realizada por alguns membros do ISEB, ao nacionaldesenvolvimentismo, pela sua associação ao imperialismo e ao desenvolvimento associado com o capital estrangeiro, a crítica ao imperialismo se reforça. Note-se que, em nenhum momento, sob a justificativa de ter como objetos de estudo a ideologia e a filosofia, Caio Navarro de Toledo referiu-se à Guerra Fria. Para o autor, é como se não tivesse ocorrido a bipolaridade das relações internacionais, a corrida armamentista, a corrida espacial (o Sputnik e a cadela Laika estão no centro das atenções nesse período), a Conferência de Bandung, exigindo espaço para os países Não-Alinhados ou a Revolução Cubana, que trouxe a latino-americanização da Guerra Fria. Esses elementos, todos, reforçaram o nacionalismo no Brasil. Se o nacionalismo, por pressuposto, oculta as contradições de classe (e essa era uma análise que muito poucos conseguiam vislumbrar naqueles meados

\footnotetext{
${ }^{12}$ Num segundo momento, algo próximo do período que propomos como nacional-reformista, ao lado do latifúndio agrário-exportador estará presente, com maior veemência, o imperialismo, em especial o estadunidense.

${ }^{13}$ O mesmo período é denominado por Lúcio Flávio de Almeida de "nacionalismo triunfante" (ALMEIDA, 2006, p. 33; 311).
} 
da década de 1950), ele pode reforçar o antiimperialismo. O subdesenvolvimento volta a ser atacado, não mais apenas pela via do desenvolvimento, que se mostrou ineficaz, mas pela via da libertação nacional. Se não há uma alteração estrutural nessa modificação como já sabia Toledo em 1977 quando escreveu a primeira edição de seu livro - isso não era tão claro assim no período estudado. Para aqueles intelectuais, de fins dos anos 1950 e início dos 1960, o nacionalismo poderia ter um caráter revolucionário.

Em argumentação próxima àquela de Caio Navarro de Toledo, Vânia Maria Losada Moreira verifica ter havido, no último ano do Governo Juscelino Kubitschek, um importante ponto de inflexão no movimento nacionalista. Avançando em relação ao trabalho de Toledo, por perceber uma evolução paralela, no nacionalismo, entre a vertente liberal (ISEB) e o nacionalismo econômico (não é demais lembrar que Toledo faz a análise sempre em relação ao desenvolvimento do ISEB, separando-o em três períodos), Moreira vê, na eleição de 1960, o rompimento entre as duas vertentes nacionalistas. Para a autora, assim como para Toledo, em certa medida, a razão foi a reavaliação do papel do capital estrangeiro no desenvolvimento nacional. A partir dessas conclusões, os nacionalistas econômicos, ainda no Governo JK, começaram a articular um novo discurso:

(...) propuseram inúmeras políticas disciplinares aos investimentos diretos de capital: o controle sobre a remessa de lucros, royalties e dividendos para minimizar o impacto da drenagem de recursos para fora do país; a exclusividade de investimentos estatais em setores estratégicos da economia, como o setor de energia; e a política externa independente, isto é,desvinculada dos interesses tanto do bloco capitalista, liderado pelos Estados Unidos, quanto do socialista, capitaneado pela então União Soviética, para garantir uma industrialização centrada antes nos interesses internos do que na bipolarização internacional da Guerra Fria (MOREIRA, 2003, p. 172-173).

Difundir esse novo discurso para os setores populares. Colocar esse novo discurso em prática. Realizar uma virada reformista no nacionalismo econômico, enfatizando entre seus componentes uma nova forma de organização da política exterior do país. É disso que vai tratar nossa próxima seção, ao abordar o nacional-reformismo.

\section{O NACIONAL-REFORMISMO.}

Com o amadurecimento dessa vertente do nacionalismo brasileiro (nacionalismo econômico), os elementos que o constituem começam a se reordenar. Momentos de ruptura com o nacional-desenvolvimentismo já podem ser encontrados, com a eclosão da Revolução Cubana, em plano externo, e com a eleição de Jânio Quadros, derrotando Henrique Teixeira Lott, no plano interno. 
A Revolução Cubana (1959) realiza-se, primeiramente, de forma antioligárquica, retirando o poder das mãos do pequeno grupo que governava a Ilha e que mantinha relações muito próximas com os Estados Unidos. Não demora, ao processo revolucionário cubano, tomar medidas antiimperialistas, que tiveram grandes repercussões na América Latina. Os setores nacionalistas econômicos começavam a perceber, no imperialismo, notadamente o estadunidense, um empecilho para o desenvolvimento. Começara-se a perceber, com mais força, que não era apenas o latifúndio agrário-exportador que obstaculizava o desenvolvimento do país. O imperialismo estadunidense, que ganhou cadência com a Revolução Cubana, mostrava-se como objeto de combate. A Operação Pan-Americana (OPA), do Ministério das Relações Exteriores, começava a sofrer críticas dos setores nacionalistas econômicos, por manter uma postura essencialmente "americanista", vendo, nos Estados Unidos, um parceiro prioritário para as relações comerciais e diplomáticas. O nacionalismo, almejando a defesa da soberania nacional, começava a rearticular um discurso de independência nas relações internacionais, rompendo com o paradigma "americanista", que via nos Estados Unidos a melhor solução na busca pelo desenvolvimento por vias internacionais. Começavam a surgir novas idéias, algumas inclusive na busca de um novo paradigma, talvez o próprio "globalista", do qual a Política Externa Independente se tornaria o exemplo consubstanciado.

Com a eleição de 1960, todos os setores nacionalistas uniram-se na candidatura Lott. A derrota foi importante momento de inflexão, gerando necessários esforços organizados para uma nova configuração do discurso nacionalista. Não bastava mais apenas o país desenvolver-se economicamente, se os resultados desse desenvolvimento não melhorassem as condições de vida do povo brasileiro. Povo que, nesse momento, torna-se o elemento definidor do nacionalismo, pois a nação já fora construída. É hora de se reformar o que tinha sido realizado.

Embora tenhamos optado, deliberadamente, pelo enfoque no ISEB, na construção do nacionalismo brasileiro como o centro, por excelência, da idéia de forjar uma consciência nacional, pelo menos outros dois centros tiveram importante papel na elaboração do nacionalismo brasileiro, com destaque para a transformação que passou a sofrer no limiar dos anos 50, realizando-se como um nacionalismo a favor de reformas no capitalismo brasileiro. Embriões do nacional-reformismo, além do ISEB, em sua última fase, e responsáveis pelas articulações capazes de alocar reformas no desenvolvimento conquistado, foram o Partido Comunista Brasileiro e a Frente Parlamentar Nacionalista. 
Mesmo sendo posto na ilegalidade, ainda em 1947, o Partido Comunista Brasileiro desempenhava um papel importante, ao longo do período 1945-1964. Já na primeira eleição presidencial, seu candidato alcançara $10 \%$ dos votos. Contava com destacadas personalidades do mundo intelectual brasileiro. Após o suicídio de Getúlio Vargas, teve na luta pela industrialização uma das suas mais importantes bandeiras, talvez só comparável ao papel que atribuía à luta contra o latifúndio e o imperialismo, presente desde a sua fundação, em 1922.

Com as "teses de 1958", os comunistas brasileiros passaram a defender uma ampla aliança nacionalista, inclusive com o que, à época, denominava-se burguesia nacional. É dessa época que, em artigo na Revista Brasiliense (organizada por Caio Prado Júnior), Hermes Lima, que não era comunista, afirmava: "O nacionalismo não supõe exclusivamente o Estado intervencionista. Supõe, isto sim, o Estado na liderança, no comando da política de desenvolvimento, no estímulo direto ou indireto de medidas promocionais de desenvolvimento" (PÉCAUT, 1990, p. 144). O que Hermes Lima propõe, e que os comunistas aceitam ao menos discutir, é o papel do Estado como promotor do desenvolvimento nacional, sendo organizado a partir de uma aliança nacionalista.

Se os comunistas nutriam esses sentimentos antiestadunidenses, fazendo deles um dos componentes essenciais de sua participação nas frentes nacionalistas, perspectiva instigante nos abre Carla Simone Rodeghero em seu estudo feito a partir dos documentos elaborados pelos postos diplomáticos estadunidenses no Brasil. A autora percebe que, no início dos anos 1960, as preocupações dos Estados Unidos no Brasil não se dão apenas com o comunismo em estrito sentido, mas sim em relação ao nacionalismo que se estava transformando:

\footnotetext{
O perigo comunista parece fazer sentido quando se observa que esses norte-americanos usavam um conceito mais largo de comunismo no que se refere ao Brasil, englobando manifestações de nacionalismo e/ou antiamericanismo. E, em nível continental, isso se mesclava à preocupação em manter a América Latina longe da expansão comunista. A 'perda' de Cuba já havia acontecido e o desdobramento dos acontecimentos políticos no Brasil teria conseqüências no relacionamento norteamericano com o conjunto dos países da América Latina (RODEGHERO, 2007, p. 164).
}

Assim, acreditavam que o nacionalismo do início dos anos 1960, com suas posturas antiestadunidenses, poderiam fazer do Brasil uma nova Cuba. E projetavam - em razão da experiência cubana - que o Brasil poderia em um segundo momento se declarar socialista. Em nada os tranqüilizava a Política Externa Independente, com sua retomada de relações diplomáticas com o Leste Europeu e a URSS. 
Já nos meios políticos institucionalizados no Estado, a Frente Parlamentar Nacionalista constitui-se, em 1956, de 55 deputados federais (DELGADO, 2007, p. 368). Embora tenha existido, ao longo dos mandatos dos presidentes Juscelino Kubitschek e Jânio Quadros, foi ao longo do período de João Goulart que "a FPN ganhou maior dinâmica e melhor visibilidade" (DELGADO, 2007, p. 370-371). Nesse período, ampliou seu número de integrantes para 61 deputados federais, sendo o partido hegemônico, em seu interior, o PTB, com 30 deputados federais (DELGADO, 2007, p. 372). ${ }^{14}$

A Frente Parlamentar Nacionalista era muito influente durante o Governo Goulart. Desde 1960, estava comprometida com as Reformas de Base, conquanto houvesse divergências entre seus membros em relação à reforma agrária. Embora Lucília de Almeida Neves Delgado explique essas divergências no nível partidário, sendo os vinculados ao PTB favoráveis à reforma no campo, e os do PSD, PRP e PR não terem dado o apoio integral a esta, acreditamos que a resposta a essa divergência encontra-se oculta pelo caráter próprio do nacionalismo, capaz de unir distintos projetos políticos, por vezes, inclusive, antagônicos, encobrindo suas diferenças apenas até certo ponto. Apesar disso, inegável é o papel desempenhado pela Frente, pois "contribuiu enormemente para a difusão de teses nacionalistas, reformistas e desenvolvimentistas, tanto nos poderes Executivo e Legislativo federais, como na sociedade civil" (DELGADO, 2007, p. 373).

As contribuições do ISEB, somadas às do PCB e da FPN, possibilitaram outro desdobramento do conceito de nacionalismo: o de nacional-reformismo. A nosso ver, este é o termo mais próximo da realidade do Brasil no início dos anos 1960. O projeto político do presidente João Goulart pode ser descrito como tendo caráter nacional-reformista em razão de pugnar a interferência do Estado na realização de reformas sociais, políticas e econômicas, visando ao desenvolvimento do país, bem como à sistematização da Política Externa Independente, que tinha como um dos preceitos fundamentais o desenvolvimento econômico, a partir das relações internacionais do Brasil, no contexto da Guerra Fria.

Embora muitas das reformas de base já tramitassem no Congresso Nacional, desde 1956, foi apenas com a posse de João Goulart (possível somente com o aceite da tutela parlamentarista) que a discussão sobre a implantação tomou consistência e caráter sistêmico. Houve avanços e recuos ao longo do Governo Goulart, na implantação das reformas de base. Conforme os setores nacionalistas pressionavam por sua implantação, os

\footnotetext{
${ }^{14}$ Além dos deputados do PTB, Lucília de Almeida Neves Delgado nos informa de 12 do PSD, 10 da UDN, e 9 de outros partidos, como o PSP, PR, PSB.
} 
setores conservadores endureciam suas obstruções. De um lado intelectuais, sindicatos, partidos de esquerda e ligas camponesas exigiam sua implementação; de outro, entidades empresariais, Instituto de Pesquisas e Estudos Sociais (IPES), Instituto Brasileiro de Ação Democrática (IBAD) (ambos os institutos patrocinados com verbas estadunidenses) e partidos conservadores se opunham a sua realização. Impossível se referir ao início dos anos 1960 no Brasil sem apontar o papel desempenhado pelas reformas de base. No dizer de Daniel Aarão Reis Filho, são elas:

(...) a reforma agrária, a bandeira mais brandida, prevendo a utilização racional da terra e sua distribuição aos camponeses sem terra ou com pouca terra; a reforma urbana, capaz de disciplinar o uso e a posse do solo urbano, e de controlar a ganância e o abuso dos proprietários de imóveis e de especuladores de terrenos; a reforma tributária, deslocando para o imposto de renda o peso da carga fiscal, de modo a despejar nos mais ricos ônus maiores, proporcionais a seus bens; a reforma eleitoral, conferindo voto aos analfabetos, que, na época, segundo as estatísticas, representavam quase metade da população economicamente ativa; a reforma bancária, fazendo com que as estruturas financeiras direcionassem o crédito segundo critério social e nacionalmente orientados; $a$ reforma do estatuto do capital estrangeiro, privilegiando-se o capital produtivo, devidamente direcionado para áreas determinadas, definidas de acordo com os interesses do país, e taxando a remessa de lucros para o exterior; a reforma universitária, colocando a ciência e a pesquisa a serviço da sociedade brasileira e dos chamados interesses nacionais (REIS FILHO, 2001, p. 329330).

Como se pôde observar, a luta pelas reformas mobilizava toda a nação. Para os setores populares, representaria avanços consideráveis nas suas condições de vida. Para os grupos dominantes, poderia representar perdas irreparáveis para sua sustentação. Todas as reformas apelavam, em maior ou menor grau, implícita ou explicitamente, ao aperfeiçoamento do capitalismo no Brasil, utilizando-se do nacionalismo com vista à maior incorporação social. Nenhuma delas, nem por um momento, aproximava-se de medidas socialistas ou mesmo comunistas, como eram genericamente acusadas pelos que as combatiam. Como assevera Carla Rodeghero: "Tal combate, todavia, parecia estar mais ligado aos perigos representados pelo nacionalismo e pelo antiamericanismo do que pelo comunismo" (RODEGHERO, 2007, p. 164). Não era o comunismo que os setores dominantes da sociedade queriam bloquear, embora ele fosse a tônica do discurso; o inimigo era o nacionalismo, mas não o mesmo nacionalismo dos anos 40/50. O inimigo era o nacional-reformismo.

A isso somava-se a Política Externa Independente, pois, contrariamente ao que aconteceu à PEI, no Governo Quadros, durante o Governo Goulart "a política externa não estava desvinculada da política interna” (MUNTEAL; VENTAPANE \& FREIXO, 2006, p. 35). A mesma soberania que se dizia buscar internamente manifestava-se externamente, ao 
respeitar a soberania de Cuba frente às tentativas estadunidenses de expulsá-la do quadro da Organização dos Estados Americanos (OEA); a mesma autonomia que o nacionalismo reformista defendia para o Brasil, frente ao capital externo, era defendida nas relações externas, ao comercializar produtos com o Leste Europeu, naquela considerada a fase mais quente da Guerra Fria. Embora muitos de nós saibamos, desde muito tempo, que as contradições fundamentais da sociedade são aquelas que se operam no nível das lutas de classe, não seria uma análise correta do período aquela que ocultasse a existência da Guerra Fria. Ao afirmarem que o nacional-reformismo simplesmente deslocou o conflito de classes, perde-se a perspectiva histórica, dado que "o privilégio concedido à 'libertação nacional' não tinha, então, valor algum de álibi, visando evitar a luta de classes; muito simplesmente, o Brasil vivia a hora do advento do Terceiro Mundo" (PÉCAUT, 1990, p. 180). O nacionalismo econômico e sua evolução reformista não poderiam deixar de lado sua principal configuração: o desenvolvimento a partir de bases nacionais. E este era um dos objetivos da Política Externa Independente.

Em 2005, ao se completarem 50 anos da fundação do ISEB, Caio Navarro de Toledo organizou um livro intitulado Intelectuais e política no Brasil: a experiência do $I S E B$, composto de depoimentos de personagens importantes desse Instituto, e de artigos acadêmicos, analisando as suas contribuições. Em seu artigo, Caio Toledo parece tentar responder a algumas perguntas que ficaram soltas no trabalho maior. Seu foco, neste novo trabalho, será os anos 1960, em especial o "governo Goulart - momento em que a instituição assumiu abertamente uma direção e uma orientação de esquerda -, o ISEB passou também a empunhar com vigor a bandeira das reformas sociais (agrária, bancária, política, administrativa, universitária, etc)" (TOLEDO, 2005, p. 149). ${ }^{15}$

A tese central do seu trabalho de trabalho é uma contraposição entre o ISEB e o IPES. Utilizando-se da categoria aparelho ideológico, o ensaísta alinha o ISEB a uma variante do Estado, enquanto o IPES estaria alinhado com a sociedade civil. Segundo o autor, o IPES era partidário de uma democracia liberal, com reduzida participação popular, além de condenar as reformas de base e as "tentativas legislativas de disciplinar o capital estrangeiro e a prática de uma política externa soberana e independente" (TOLEDO, 2005, p. 151). Sendo o Governo Goulart um governo de muitas lutas sociais, Caio Navarro de Toledo procura evidenciar mais uma delas: a luta entre intelectuais.

\footnotetext{
15 Há uma significativa diferença entre a maneira como o autor abordou essa fase do ISEB no trabalho anterior, e como está abordando agora, com traços muito mais positivos.
} 
O que outrora o autor designava como "último ISEB", agora passa a ser incorporado pelo nacional-reformismo (TOLEDO, 2005, p. 152). Assim, mesmo em uma análise sem a mesma densidade a anterior - preocupada com o período nacionaldesenvolvimentista - Caio Navarro de Toledo avança, ao incorporar algumas críticas relativas à falta de contextualização histórica e política do trabalho anterior (TOLEDO, 2005, p. 164 nota 37). Mesmo esse artigo não tendo a mesma solidez filosófica do outro, considerando seu artigo clássico, ele mostra avanços consideráveis, ao dar uma dimensão concreta à análise do período ora estudado. Procurando suprir uma lacuna importante da história do ISEB, deixada aberta por ele mesmo, Caio Toledo a enriquece incorporando ao seu trabalho teórico a conjuntura histórica.

\section{CONCLUSÃO}

Ao abordar o fenômeno do nacionalismo neste trabalho, procuramos dimensioná-lo de forma teórica e histórica. Para tanto, valemo-nos das contribuições da discussão realizada por autores como Ernest Gellner, Benedict Anderson e Eric Hobsbawm. Estes autores, em especial a partir da década de 1980, contribuíram para o amadurecimento das discussões em torno de um conceito tão complexo nacionalismo.

Ao analisar o nacionalismo no Brasil, ao tempo da experiência democrática de 1945-1964, foi possível - em especial a partir das conclusões de Hobsbawm - demonstrar como tal conceito modificou-se, ao longo do tempo, que, embora breve, cronologicamente, foi extremamente denso, em termos de lutas políticas, sendo o nacionalismo a baliza entre dois projetos de nação.

Com o Governo Getúlio Vargas (1951-1954), pudemos perceber a emergência do conceito, nas lutas políticas. Ao implementar uma maior participação do Estado no desenvolvimento nacional, o projeto do início dos anos 1950 trabalhava de forma embrionária com o nacionalismo, sendo a origem das discussões que este conceito propiciou ao longo da democracia brasileira da época.

Ainda no Governo Café Filho, mas especialmente ao longo do Governo Juscelino Kubitscheck, o nacionalismo foi forjado enquanto ideologia pelos intelectuais do ISEB. Esta Instituição, embora autônoma, mantinha fortes vínculos com a administração JK. Seus atores foram os grandes divulgadores da idéia do nacional-desenvolvimentismo; através dessa ideologia, procuravam legitimar o desenvolvimento do Brasil em bases nacionalistas.

Com o fim do Governo JK, a crítica da experiência nacional-desenvolvimentista foi 
realizada, inclusive por alguns autores vinculados ao ISEB. A ilusão desenvolvimentista teve fim. Alguns intelectuais do ISEB, juntamente com intelectuais do PCB e parcelas da sociedade brasileira, perceberam os limites concretos do nacional-desenvolvimentismo: que o desenvolvimentismo se realizara com relativo sucesso, porém, às expensas de seu caráter nacional.

No Governo Goulart, uma nova transformação tomou o nacionalismo no Brasil. Com as críticas elaboradas numa dimensão que priorizava um discurso de reformas no capitalismo para integrar maiores parcelas da sociedade à nação foi se consubstanciando o caráter distributivista do nacionalismo, o que radicalizou o conceito, tanto teórica quanto concretamente, ao terem, as lutas sociais do período, também, se radicalizado. Foi isso que tentamos demonstrar ao longo deste trabalho.

\section{BIBLIOGRAFIA}

ACTON, Lord. "Nacionalidade". In: BALAKRISHNAN, Gopal. Um mapa da Questão Nacional. Rio de Janeiro: Contraponto, 2000, p. 23-43.

ALMEIDA, Lúcio Flávio Rodrigues de. Uma ilusão de desenvolvimento: nacionalismo e dominação burguesa nos anos JK. Florianópolis: Ed. da UFSC, 2006.

ANDERSON, Benedict. Nação e Consciência Nacional. São Paulo: Ática, 1989.

BALAKRISHNAN, Gopal (org.). Um mapa da Questão Nacional. Rio de Janeiro: Contraponto, 2000.

BAUER, Otto. “A nação". In: BALAKRISHNAN, Gopal. Um mapa da Questão Nacional. Rio de Janeiro: Contraponto, 2000, p. 45-83.

DELGADO, Lucília de Almeida Neves. "Nacionalismo como projeto de nação: a Frente Parlamentar Nacionalista (1956-1964)”. In: FERREIRA, Jorge \& REIS, Daniel Aarão (orgs.). Nacionalismo e reformismo radical (1945-1964). Rio de Janeiro: Civilização Brasileira, 2007, p. 357-376.

GELLNER, Ernest. Nações e nacionalismo: trajectos. Lisboa: Gradiva, 1983.

. 'O advento do nacionalismo e sua interpretação: os mitos da nação e da classe'. In: BALAKRISHNAN, Gopal. Um mapa da Questão Nacional. Rio de Janeiro: Contraponto, 2000.

HOBSBAWM, Eric. Nações e nacionalismo desde 1780. $3^{\text {a }}$ ed. Rio de Janeiro: Paz e Terra, 2002. 
"Etnia e nacionalismo na Europa de hoje". In: BALAKRISHNAN, Gopal. Um mapa da Questão Nacional. Rio de Janeiro: Contraponto, 2000, p. 271-282.

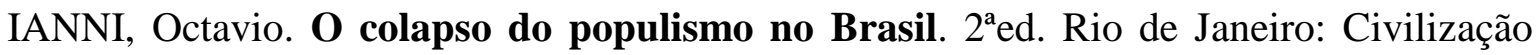
Brasileira, 1971.

MOREIRA, Vânia Maria Losada. "Os anos JK: industrialização e modelo oligárquico de desenvolvimento rural". In: FERREIRA, Jorge \& DELGADO, Lucília (orgs.). O Brasil Republicano - O tempo da experiência democrática (da democratização de 1945 ao golpe civil-militar de 1964.). Rio de Janeiro: Civilização Brasileira, 2003, 155-194.

MUNTEAL, Oswaldo; VENTAPANE, Jacqueline \& FREIXO, Adriano de (orgs.). O Brasil de João Goulart: um projeto de nação. Rio de Janeiro: Contraponto, 2006.

NEVES, Lucília de Almeida. "Trabalhismo, nacionalismo e desenvolvimentismo: um projeto para o Brasil". In: FERREIRA, Jorge (org.). O populismo e sua história: debate e crítica. Rio de Janeiro: Civilização Brasileira, 2001, 167-203.

PÉCAUT, Daniel. Os intelectuais e a política no Brasil: entre o povo e a nação. São Paulo: Ática, 1990.

REIS FILHO, Daniel Aarão. "O colapso do colapso do populismo ou a propósito de uma herança maldita". In: FERREIRA, Jorge (org.). O populismo e sua história: debate e crítica. Rio de Janeiro: Civilização Brasileira, 2001, p.319-377.

RODEGHERO, Carla Simone. Capítulos da Guerra Fria: o anticomunismo brasileiro sob o olhar norte-americano (1945-1964). Porto Alegre: Editora da UFRGS, 2007.

SCHWARTZMAN, Simon. "Seleção e introdução". In: O Pensamento Nacionalista e os “Cadernos de Nosso Tempo". Brasília: Editora da UNB, 1979, p. 3-6.

SMITH, Anthony D. "O nacionalismo e os historiadores". In: BALAKRISHNAN, Gopal. Um mapa da Questão Nacional. Rio de Janeiro: Contraponto, 2000, p. 185-208.

TOLEDO, Caio Navarro de. ISEB: fábrica de ideologias. $2^{\mathrm{a}}$ ed. Campinas: Editora da Unicamp, 1997.

"ISEB: ideologia e política na conjuntura do golpe de 1964". In: TOLEDO, Caio Navarro de (org.). Intelectuais e política no Brasil. A experiência do ISEB. Rio de Janeiro: Revan, 2005, p. 137-164.

WEFFORT, Francisco Corrêa. O Populismo na política brasileira. $5^{\text {a }}$ ed. Rio de Janeiro: Paz e Terra, 2003. 